\title{
A promoção do direito fundamental ao meio ambiente de trabalho equilibrado mediante tutela específica
}

\author{
The promotion of the fundamental right of balanced \\ work environment under legal guardianship
}

Vitor Salino de Moura Eça Pontifícia Universidade Católica de Minas Gerais (PUC), Belo Horizonte/MG - Brasil.

Aline Carneiro Magalhães Carvalhido
Pontifícia Universidade Católica de Minas
Gerais (PUC), Belo Horizonte/MG - Brasil.

Flávia Aparecida Oliveira Pierre Universidade Federal de Juiz de Fora (UFJF) Juiz de Fora/MG - Brasil.

Resumo A partir de uma análise do ordenamento jurídico pátrio contemporâneo, deparamo-nos com um amplo arcabouço normativo garantidor da proteção do meio ambiente do trabalho e da saúde do trabalhador, direitos humanos fundamentais de terceira geração, essenciais para a melhoria da sua condição social. O estágio atual de amparo legal foi fruto de um longo percurso histórico de busca pela tutela dos citados bens jurídicos, iniciado em um passado não muito distante de omissão normativa, mas, que progrediu à medida que a dignidade da pessoa humana e o valor social do trabalho passaram a exercer um papel de centralidade no ordenamento jurídico. Apesar disso, diuturnamente acontecem inúmeros acidentes do trabalho e doenças ocupacionais que geram 
deletérios efeitos para o trabalhador e para a sociedade como um todo, em regra, fruto do não cumprimento das normas de saúde e segurança pelos seus destinatários. Diante dessa realidade, emerge a tutela inibitória como instrumento de prevenção dos infortúnios laborais e, por conseguinte, efetivação dos direitos essenciais do trabalhador a um meio ambiente do trabalho equilibrado, o qual deve ser usufruído in natura e não substituído por seu equivalente pecuniário.

Palavras-chave: Meio ambiente do trabalho. Acidente do trabalho. Prevenção. Tutela Inibitória.

Abstract As from a comprehensive review of the current Brazilian juridical-constitutional order, we clearly identify an extensive standardsetting instrument aimed to ensure the environmental health and labor protection of the workforce as well as basic human rights of third generation that are essential for the improvement of its social condition. The current legal relief scenario was originated from a long historical path of search to protect legal assets of normative omission, initiated not long before, but that have progressed as the dignity of the human being and the social core values of work began to play a central role in the legal system. In spite of the before mentioned, several accidents and occupational diseases are frequently reported. This has serious impacts not only to the workforce lifetime expectation but also for the entire society. In reality, most of the time as a result of the non-compliance of the health and safety rules that are not being followed by the workforce itself. Before this scenario, the inhibitory legal action is hence created as a mean not only to prevent labor woes but also to enforce essential worker rights for a proper balanced work environment that in fact should be throughly enjoyed and not traded off by pecuniary advantages.

Key-words: Work environmental. Ocupational accident. Prevention. INHIBITORY LEGAL ACTION. 


\section{INTRODUÇÃO}

Desde a origem da relação entre empregado e empregador, em meados do século XVIII, na Europa, em um contexto de Revolução Industrial, capitalismo incipiente e liberalismo econômico, a saúde do obreiro é tema de suma importância, suscitando discussões e debates e, mesmo diante de uma trajetória de avanços legais e práticos na sua proteção, ainda hoje é expressiva a luta por um ambiente de trabalho equilibrado. ${ }^{1}$

O meio ambiente do trabalho deve oferecer condições para que o empregado execute suas tarefas com saúde, segurança física e mental, livre de infortúnios, ameaças e agravos.

Nessa perspectiva e em relação ao nosso ordenamento jurídico, percebemos que ele garantiu amplo conjunto normativo protetivo àqueles bens, tendo a tutela ao meio ambiente de trabalho natureza jurídica de direito humano fundamental, que carece diuturnamente de concretização.

Os acidentes e doenças do trabalho constituem ofensa à saúde e à integridade do trabalhador e causam danos materiais e imateriais que produzem impacto na sua vida pessoal e profissional, além das reper-

\footnotetext{
Para uma compreensão do tema em uma perspectiva de Revolução Industrial na Europa, sugere-se o filme Daens: um grito de Justiça, produzido em 1992 (Bélgica/ França/Holanda) que narra a luta de um padre belga no final do século XIX contra as condições miseráveis que viviam as famílias operárias e as precárias condições de trabalho nas fábricas. SINOPSE: Reflexões sociológicas: A segunda metade do século XIX é marcada pela consolidação do sistema de produção capitalista. Considerado por historiadores como a Segunda Revolução Industrial, esse período apresentou grande avanço tecnológico e científico. Com isso, naturalmente, o mundo do trabalho também sofrera profundas transformações. Sob essa nova ordem socioeconômica, homens, mulheres e crianças, para sobreviverem, viram-se obrigados a vender o único bem que lhes restavam: sua força de trabalho. Para desenvolver suas empresas, os industriais precisavam de liberdade econômica, ampliação dos mercados consumidores e mão de obra barata e com o objetivo de aumentar os lucros pagavam aos operários salários muito baixos, oferecendo péssimas condições de trabalho. Com os ideais implantados pelo padre Deans, a sociedade passou a se movimentar, gerando conflitos entre operários e empresários. Disponível em: http:// www.sociologia.seed.pr.gov.br/modules/conteudo/conteudo.php? conteudo $=678$. Acesso em: 24 out. 2016.
} 
cussões para o empregador, previdência social, serviço de saúde e sociedade como um todo, especialmente porque muitos dos infortúnios têm como vítimas jovens recém ingressados no mercado de trabalho. ${ }^{2}$

Nesse contexto emerge a prevenção de acidentes e doenças do trabalho como uma prioridade social, especialmente para o empregador e empregado, que encontra na tutela específica um importante instrumento de concretização do direito humano fundamental ao meio ambiente de trabalho equilibrado.

A aplicação subsidiária dos artigos 536 e 537 do novo Código de Processo Civil (NCPC) - que prevê a tutela específica ou a obtenção de tutela pelo resultado prático equivalente - ao Direito Processual do Trabalho, encontra fundamento no art. 769 da Consolidação das Leis do Trabalho (CLT) e, em última análise, no princípio constitucional da efetividade dos direitos humanos e da tutela jurisdicional.

Dentro desse contorno teórico, o presente artigo tem como objetivo analisar a promoção do direito fundamental ao meio ambiente de trabalho equilibrado por meio do uso da tutela inibitória. Para tanto, no primeiro tópico conceituaremos o meio ambiente do trabalho e faremos uma relação deste com a saúde do trabalhador sob a perspectiva legal. Na sequência, abordaremos o acidente do trabalho e a necessidade de sua prevenção. Ao final, examinaremos a tutela inibitória prevista no NCPC, subsidiariamente utilizada no Processo do Trabalho, como instrumento de prevenção dos infortúnios laborais e concretização do direito fundamental do obreiro a um meio ambiente de trabalho equilibrado.

\section{Meio ambiente do trabalho}

A Lei de Política Nacional do Meio Ambiente, Lei nº 6.938/81, no artigo $3^{\circ}$., inciso I, define o meio ambiente como "o conjunto de condições, leis, influências e interações de ordem física, química e biológica, que permite, abriga e rege a vida em todas as suas formas" e determina

2 Informação disponível no site da Previdência Social - Anuários Estatísticos: $\underline{\mathrm{http}: / /}$ www.previdencia.gov.br/dados-abertos/dados-abertos-sst/ Acesso em: 29 jul. 2016. 
que a responsabilidade pelos prejuízos a ele causados é de natureza objetiva, conforme se extrai do seu artigo $14, \S^{\circ}$. $^{3}$

O meio ambiente equilibrado é um direito humano fundamental, ${ }^{4}$ imprescindível à condição humana, e como tal merece a proteção do Estado e da sociedade como um todo. Neste sentido, aduz Ferreira Filho:

De primeira geração são os direitos civis e políticos liberdades públicas negativas perante o Estado. Depois de libertado o homem das garras deste, surgiram os direitos positivos, de segunda geração - os sociais, os econômicos e os culturais - que servem para dotar o ser humano das condições materiais minimamente necessárias ao exercício de uma vida digna. De terceira geração são os direitos de solidariedade e fraternidade - a paz no mundo, o desenvolvimento econômico dos países, a preservação do meio ambiente, do patrimônio comum da humanidade e da comunicação (FERREIRA FILHO apud MELO, 2013, p. 370).

De acordo com o art. 200, VIII, da CR/88, o meio ambiente de trabalho é uma dimensão do meio ambiente. Ele está inserido no meio ambiente geral, sendo impossível alcançar qualidade de vida sem qua-

3 Lei $n^{\circ} .6 .938 / 81$, art. $14, \S 1^{\circ}$. - Sem obstar a aplicação das penalidades previstas neste artigo, é o poluidor obrigado, independentemente da existência de culpa, a indenizar ou reparar os danos causados ao meio ambiente e a terceiros, afetados por sua atividade. O Ministério Público da União e dos Estados terá legitimidade para propor ação de responsabilidade civil e criminal, por danos causados ao meio ambiente.

4 Segundo Alexandre de Moraes (1998, p. 39) os Direitos Humanos Fundamentais são "o conjunto institucionalizado de direitos e garantias do ser humano que têm por finalidade básica o respeito a sua dignidade, por meio de sua proteção contra o arbítrio do poder estatal e o estabelecimento de condições mínimas de vida e desenvolvimento da personalidade humana pode ser definido como direitos humanos fundamentais". Para José Afonso da Silva (1999, p. 182), "No qualificativo fundamentais acha-se a indicação de que se trata de situações jurídicas sem as quais a pessoa humana não se realiza, não convive e, às vezes, nem mesmo sobrevive; fundamentais do homem no sentido de que todos, por igual, devem ser, não apenas formalmente reconhecidos, mas concreta e materialmente efetivados. Do homem, não como macho da espécie, mas no sentido de pessoa humana”. 
lidade no trabalho, tampouco se atinge um meio ambiente equilibrado e sustentável, ignorando o meio ambiente do trabalho (OLIVEIRA, 2011). Pela dimensão e importância que apresenta, congrega direitos difusos, coletivos e individuais homogêneos, cuja análise deve ser feita sob a perspectiva constitucional (GEMIGNANI; GEMIGNANI, 2012).

Para Raimundo Simão de Melo (2013), o conceito de meio ambiente do trabalho deve levar em conta a pessoa do trabalhador e tudo que o cerca:

[...] quando falamos em assédio moral no trabalho, nós estamos nos referindo ao meio ambiente de trabalho, pois em um ambiente onde os trabalhadores são maltratados, humilhados, perseguidos, ridicularizados, submetidos a exigências de tarefas abaixo ou acima da sua qualificação profissional, de tarefas inúteis ou ao cumprimento de metas impossíveis de atingimento, naturalmente haverá uma deterioração das condições de trabalho, com adoecimento, do ambiente e dos trabalhadores, com extensão até para o ambiente familiar (MELO, 2013, p. 29).

A manutenção do ambiente de trabalho saudável é dever do empregador e do empregado, sendo também um direito deste, ${ }^{5}$ que carece de uma atuação conjunta e concertada de ambos para a sua promoção.

$\mathrm{O}$ meio ambiente do trabalho está relacionado de forma direta e imediata com o ser humano trabalhador no seu dia a dia, na atividade laboral que exerce em proveito de outrem e não se restringe ao local de trabalho, abrangendo também os instrumentos de trabalho, o modo de execução das tarefas e a maneira como o trabalhador é tratado pelo empregador, bem como, pelos próprios colegas de trabalho. Nas palavras de Raimundo Simão de Melo:

5 Neste sentido o art. $7^{\circ}$., inciso XXII da CR/88, que garante a redução dos riscos inerentes ao trabalho, por meio de normas de saúde, higiene e segurança; e o inciso XXVIII, que prevê seguro contra acidentes de trabalho, a cargo do empregador, sem excluir a indenização a que este está obrigado, quando incorrer em dolo ou culpa. Na mesma linha a CLT, no capítulo V, que dispõe sobre a Segurança e Medicina do Trabalho (art. 154 e seguintes). 
[...] todo trabalhador que desempenha alguma atividade, remunerada ou não, homem ou mulher, celetista, autônomo ou servidor público de qualquer espécie, porque realmente todos receberam a proteção constitucional de um ambiente de trabalho adequado e seguro, necessário à sadia qualidade de vida (MELO, 2013, p. 29).

O equilíbrio do meio ambiente do trabalho, preceito constitucional nos termos do artigo 225 da CR/88, está ancorado na salubridade do meio e na ausência de agentes que comprometam a incolumidade físico-psíquica dos trabalhadores visto que se trata de um direito que, se desrespeitado, provoca agressão a toda a sociedade, que, em última análise, é quem custeia a Seguridade Social (MELO, 2013).

Diante disso, a promoção de um meio ambiente de trabalho seguro e saudável se reveste de inequívoca socialidade, por ser evidente o predomínio do interesse social sobre o meramente individual, assim ensejando a aplicação dos princípios da boa-fé objetiva, função social do contrato, função social da empresa e função social da propriedade, visto que os efeitos provocados pelos infortúnios laborais não atingem apenas as pessoas dos contratantes, de modo que se revela insuficiente a alternativa de apenas pagar um adicional (de insalubridade ou periculosidade) ao invés de melhorar, de forma efetiva, as condições do meio ambiente do trabalho (GEMIGNANI; GEMIGNANI, 2012).

Ressalte-se, inclusive, que o pagamento de adicionais de insalubridade e periculosidade não deveria representar a "venda" da saúde do trabalhador, mas a majoração dos custos da empresa, para estimular, sob a perspectiva financeira, a eliminação dos agentes gravosos à saúde e à integridade do obreiro. Entretanto, não é isso que observamos, uma vez que muitas empresas optam pelo pagamento desses adicionais irrisórios em detrimento do investimento sério e expressivo em saúde e segurança.

Segundo Maria Lúcia Endo (2009), a proteção ao meio ambiente de trabalho tem por objeto jurídico a saúde e a segurança do trabalhador, para que desfrute a vida com qualidade, por meio de processos adequados para que se evitem a degradação e os danos à sua vida e integridade física e psíquica. 
$\mathrm{Na}$ busca pela promoção de um meio ambiente do trabalho equilibrado, em que há proteção da vida e saúde do trabalhador, é importante que se evite a ocorrência dos acidentes no ambiente de trabalho. De acordo com a doutrina (OLIVEIRA, 2011), os estudos comprovam que muitos dos acidentes do trabalho são passíveis de prevenção.

A prevenção vai de encontro à mentalidade ressarcitória pelo equivalente pecuniário hoje prevalecente, em que as empresas se limitam a pagar indenizações após a ocorrência do dano, mas que não trarão de volta a vida, a saúde, a integridade física e mental ou a capacidade para o trabalho do obreiro vítima de um infortúnio laboral.

A função promocional do Direito indica a necessidade de intensificar a atuação preventiva, formando uma nova mentalidade, com o escopo de evitar a ocorrência de acidentes e doenças ocupacionais, por considerar que assegurar meio ambiente equilibrado no local de trabalho constitui direito fundamental, albergado pela Constituição de 1988 (GEMIGNANI; GEMIGNANI, 2012).

Nesse contexto, conclui-se sobre a necessidade de privilegiar uma gestão empresarial de prevenção dos acidentes do trabalho, como instrumento de promoção de um meio ambiente do trabalho equilibrado, direito essencial dos trabalhadores e de dever dos empregadores.

\section{O MEIO AMbiente do TRABALHO E A SAÚdE DO TRABALHADOR NO ORDENAMENTO JURÍDICO PÁTRIO}

A Constituição da República de 1988 buscou tutelar todos os aspectos do meio ambiente, quais sejam, natural, artificial, cultural e do trabalho, conforme se extrai do artigo 225, e seu objeto maior é a proteção da vida em todas as suas formas, em especial a vida humana (MELO, 2013).

O meio ambiente equilibrado é, como ressaltado, um direito fundamental e como tal essencial a todos os seres humanos. De acordo com o artigo $1^{\circ}$., da $\mathrm{CR} / 88$, a dignidade da pessoa humana e o valor social do trabalho são fundamentos da República e estão diretamente ligados à noção de meio ambiente do trabalho equilibrado, pois a promoção deste representa a concretização daqueles princípios na relação empregatícia. 
Na mesma linha de raciocínio, dispõe o artigo 170 da Carta Magna que cuida da ordem econômica e tem como premissas o respeito ao meio ambiente, a valorização do trabalho humano e da livre-iniciativa, conforme os ditames da justiça social. O "constituinte de 1988 assegurou e incentivou a livre iniciativa econômica, desde que respeitados os princípios que norteiam a dignidade da pessoa humana, no caso, o respeito ao meio ambiente do trabalho" (MELO, 2013, p. 36).

A norma fundamental dispõe sobre a atuação metaindividual de proteção ao trabalhador e ao meio ambiente de trabalho, o que pode ser feito por intermédio da ação popular (art. $5^{\circ}$., inciso LXXIII), pelos sindicatos, Ministério Público do Trabalho e demais entidades autorizadas, de acordo com os artigos $8^{\circ}$., III, 127 e 129 da CR/88 (MELO, 2013).

A prevenção dos acidentes do trabalho também é trazida como direito fundamental no art. $7^{\circ}$., inciso XXII, da CR/88, segundo o qual "é direito do trabalhador urbano e rural a redução dos riscos inerentes ao trabalho, por meio de normas de saúde, higiene e segurança”.

De acordo com as normas constitucionais, a proteção do meio ambiente do trabalho está ligada diretamente à saúde e à integridade física e mental do trabalhador enquanto cidadão, visto que se trata de um direito de todos que deve ser protegido, ou seja, "o meio ambiente do trabalho deve ser sempre tomado como um bem difuso a ser tutelado" (ROCHA, 1997, p. 281).

$\mathrm{O}$ artigo 23, inciso $\mathrm{VI}$, da $\mathrm{CR} / 88$ trata do meio ambiente, no qual está inserido o meio ambiente do trabalho, dispondo ser competência comum da União, dos Estados, do Distrito Federal e dos Municípios protegê-lo, bem como, da saúde (inciso II), aí incluída a saúde ocupacional.

De acordo com Raimundo Simão de Melo (2013), o Direito Ambiental do Trabalho constitui direito difuso fundamental inerente às normas sanitárias e de saúde do trabalhador, conforme se extrai do artigo 196 da CR/88, pois as consequências provenientes de sua degradação atingem imediatamente o trabalhador e, por conseguinte, toda a sociedade. No artigo 194 da CR/88, por sua vez, a saúde foi considerada como direito social. 
Também no artigo $6^{\circ}$. da norma fundamental temos relacionados, entre outros, o trabalho, a saúde e a segurança como direitos sociais do cidadão.

No artigo 10, inciso II, " $a$ ", do Ato das Disposições Constitucionais Transitórias (ADCT) tem-se a garantia de estabilidade provisória no emprego aos representantes dos trabalhadores na Comissão Interna de Prevenção de Acidentes (CIPA), ${ }^{6}$ proteção que visa garantir a liberdade e eficácia de sua atuação na proteção do meio ambiente laboral.

A expressão qualidade de vida do trabalhador ou qualidade de vida no trabalho ganha terreno no Brasil com a $\mathrm{CR} / 88$, contemplada no artigo 200, VIII, no já mencionado artigo 225, bem como, no artigo 79 do ADCT, com o acréscimo da Emenda Constitucional n ${ }^{\circ}$. 31, de 14 de dezembro de 2000 (OLIVEIRA, 2011).

Os dispositivos citados tratam da proteção ao meio ambiente do trabalho notadamente no sentido de promover a saúde e a segurança física e mental do obreiro, mas a Constituição também trata dos aspectos reparatórios, conforme o disposto no artigo $5^{\circ}$., incisos $\mathrm{V}$ e X, de onde se extrai que é assegurado o direito à indenização por dano material e moral (e também estético) quando violados direitos personalíssimos do obreiro.

O citado artigo $7^{\circ}$., inciso XXIII, assegura adicional pelo trabalho penoso, insalubre e perigoso, como forma de encarecer o custo da mão de obra e, com isso, estimular o empregador a investir em um meio ambiente de trabalho seguro e saudável ao invés de pagar um acréscimo salarial pela sujeição do trabalhador a condições gravosas. No inciso XXVIII do mesmo artigo, é garantido para o trabalhador o direito ao seguro contra acidentes de trabalho, a cargo do empregador, sem ex-

\footnotetext{
A maioria dos estabelecimentos com mais de 19 empregados está obrigada a constituir Cipas - Portaria n ${ }^{\circ}$. 3.214/78 c/c Decreto no. 97.995/89 c/c art. 163 da CLT c/c Norma Regulamentadora (NR) 5. Outras, dependendo da sua atividade econômica (NR 5, anexos), só estão obrigadas a constituir a CIPA quando tiverem, por estabelecimento, mais de 29, 50, 100 etc., empregados (CASSAR, 2014). Segundo a NR5, a Cipa tem como objetivo a prevenção de acidentes e doenças decorrentes do trabalho, de modo a tornar compatível permanentemente o trabalho com a preservação da vida e a promoção da saúde do trabalhador.
} 
cluir a indenização a que este está obrigado, quando incorrer em dolo ou culpa, independente das reparações a cargo do órgão previdenciário oficial (MELO, 2013).

A teia normativo-protetiva ao meio ambiente do trabalho abarca normas infraconstitucionais, a exemplo da CLT, que destina capítulo próprio às regras de segurança e medicina do trabalho. $\mathrm{O}$ mencionado Título II, Capítulo V da CLT compreende os artigos 154 a 223, e trata das normas que têm por finalidade fixar condições que garantam a saúde e a segurança dos trabalhadores no ambiente de trabalho.

O Ministério do Trabalho e Emprego, por meio de normas regulamentadoras (NR's) e portarias, regulamenta questões que dizem respeito à segurança, higiene e medicina do trabalho, matérias inerentes ao meio ambiente do trabalho. E, ainda, fiscaliza o cumprimento das citadas normas por parte das empresas.

No plano internacional, também existem várias convenções da OIT ratificadas pelo Brasil que se ocupam com a temática. A Convenção 148, ratificada no ano de 1986, versa sobre a Proteção dos Trabalhadores Contra os Riscos Profissionais Devidos à Contaminação do Ar, ao Ruído e às Vibrações no Local de Trabalho e determina que a legislação nacional deve dispor sobre a adoção de medidas no local de trabalho para prevenir e limitar esses riscos. A Convenção 152, ratificada em 1990, tratou sobre a segurança e a higiene dos trabalhadores portuários e, estendendo a todas as categorias tal preocupação, a Convenção 155, que ingressou no ordenamento brasileiro em 1992, apresentou diversas normas a respeito da segurança, higiene e meio ambiente de trabalho, exigidas para todas as atividades econômicas e também determinou a adoção de medidas para promover a inclusão dessas questões em todos os níveis de ensino e treinamento, para melhor atendimento e satisfação das necessidades dos trabalhadores.

Diante desse extenso rol normativo, percebe-se a importância da existência de um meio ambiente do trabalho equilibrado, o que compreende a proteção da saúde e a integridade física e mental do empregado.

A norma dita qual o caminho deve ser seguido pelo empregador, que é de proteção e manutenção desses bens, essenciais do ser humano. 
O trabalho é elemento integrante do meio ambiente devendo, portanto, estar de acordo com os parâmetros normativos relativos a este. ${ }^{7}$ Ele deve permitir que o trabalhador exerça suas atividades diárias livre de riscos e danos.

A norma para alcançar seu desiderato precisa ser cumprida pelo destinatário, permitindo, assim, que o trabalhador usufrua efetivamente de um meio ambiente seguro e saudável.

\section{O ACIDENTE DO TRABALHO: OFENSA À SAÚDE DO TRABALHADOR}

Conceituado o meio ambiente do trabalho e identificada a sua proteção e garantia legal, passa-se a identificar alguns elementos que agridem a saúde e a integridade física e mental do obreiro, posto que ofendem o meio ambiente do trabalho equilibrado.

A lei 8.213/91 no artigo 19 define o acidente do trabalho, também denominado acidente típico ou acidente-tipo, como aquele que ocorre pelo exercício do trabalho a serviço da empresa ou pelo exercício do trabalho dos segurados especiais, provocando lesão corporal ou perturbação funcional que cause a morte, perda ou redução permanente ou temporária da capacidade para o trabalho.

No acidente típico, os efeitos danosos são normalmente imediatos e o evento é perfeitamente identificável, tanto com relação ao local da ocorrência quanto no que tange ao momento do sinistro. Porém, há casos em que a perturbação funcional não é percebida de imediato, podendo haver manifestação tardia com real demonstração do nexo etiológico com o acidente ocorrido (OLIVEIRA, 2014).

\footnotetext{
Podemos afirmar que o trabalho prestado com respeito às normas de saúde e segurança, além das outras que formam um rol de direitos fundamentais, confere dignidade ao trabalhador. De acordo com Ledur "o direito a um posto de trabalho, com remuneração condigna, constitui condição sine qua non para que a imensa maioria dos indivíduos possa exercer o direito fundamental que está no princípio de todos, o direito à própria vida" (1998, p. 167) e complementa o autor dizendo que "[...] somente na medida em que as pessoas puderem prover dignamente a seu sustento e ao de sua família estarão aptas a influírem decisivamente na conformação do seu espaço vital" (1998, p. 96).
} 
Também são consideradas acidente do trabalho as entidades mórbidas previstas no art. 20 da Lei $n^{\circ}$. 8.213/91, quais sejam, a doença profissional e a doença do trabalho.

A doença profissional, também chamada de tecnopatia ou ergopatia, é aquela típica de determinada profissão e basta comprovar a prestação do serviço na atividade e o acometimento da doença para a sua ocorrência, por exemplo, o caso do empregado de uma mineradora que trabalha exposto ao pó de sílica e contrai a silicose (OLIVEIRA, 2014).

A doença do trabalho, também chamada de doença profissional atípica ou mesopatia, tem origem na atividade do trabalhador e decorre das condições específicas do ambiente de trabalho ou da forma em que o trabalho é executado, sem estar vinculada diretamente a determinada profissão. É o caso, por exemplo, do grupo atual das LER/DORT que podem acometer obreiros de diversas profissões.

Desse modo, a lei definiu acidente típico, doença profissional, doença do trabalho e outras hipóteses que se equiparam a ele - os chamados acidentes do trabalho por equiparação legal ${ }^{8}$ previstos no art. 21 da Lei 8.213/1991.

O agravo à saúde do trabalhador pode surgir por fatores relacionados ao trabalho exercido, ou seja, o labor atua como concausa aliado a um fator preexistente, concomitante ou superveniente que gera o prejuízo à saúde do trabalhador.

Nas palavras de Vólia Bomfim Cassar:

As doenças profissionais, os acidentes de trabalho, as enfermidades físicas e psíquicas e a redução da capacidade laborativa muitas vezes decorrem das más condições em que o trabalho se realiza ou do ambiente hostil de trabalho. Acresça-se a isso as jornadas excessivas, a postura inadequada na execução do serviço, a mecanização do trabalho; a supressão ou redução das pausas e descansos; a falta de alimentação adequada; a cobrança de maior produtividade; as tarefas repetitivas; os agen-

8 Cumpre ressaltar que estes não têm o condão de atrair a responsabilidade do empregador para fins de indenização, entretanto têm efeitos previdenciários. 
tes químicos, físicos e biológicos do ambiente de traba1ho. Todos esses fatores abalam a saúde do empregado (CASSAR, 2014, on-line).

Os citados eventos danosos quebram o equilíbrio do meio ambiente do trabalho e geram deletérias consequências sociais, econômicas, trabalhistas e previdenciárias, a exemplo do pagamento de auxílio doença, auxílio acidente e aposentadoria por invalidez, indenizações por danos morais, materiais e/ou estéticos na seara laboral, perda de mão de obra economicamente ativa, paralisação da produção, gastos com atendimento médico-hospitalar, transtornos pós-traumáticos pela vítima e/ou sua família (a depender da gravidade do acidente), gastos com multa aplicada pela fiscalização do trabalho pelo descumprimento de normas de saúde e segurança, dispêndio com ações regressivas acidentárias propostas pelo Instituto Nacional do Seguro Social (INSS) em face do empregador negligente com seu dever de segurança, majoração da contribuição previdenciária para o Seguro Acidente do Trabalho (SAT) através do Fator Acidentário de prevenção (FAP) entre outras.

Diante da ofensa a direitos fundamentais - meio ambiente do trabalho equilibrado, saúde, dignidade do trabalhador - e dos deletérios efeitos causados pelos infortúnios laborais, faz-se necessária uma atuação efetiva voltada para a prevenção dos acidentes do trabalho e doenças ocupacionais.

\section{A PREVENÇÃo dOS INFORTÚnios LABORAIS}

A prevenção, segundo Raimundo Simão de Melo (2013, p. 54), "significa adoção de medidas tendentes a evitar riscos ao meio ambiente e ao ser humano. O princípio da prevenção é considerado um mega princípio ambiental" e com o da educação e o do poluidor-pagador, está contido nas disposições do artigo 225 da CR/88.

Sua importância reside no fato de que é um preceito fundamental, visto que os danos ambientais são, na maioria das vezes, irreversíveis e irreparáveis (FIORILLO apud MELO, 2013). No que diz respeito ao 
meio ambiente do trabalho, o trabalhador está sujeito aos prejuízos decorrentes dos danos ambientais, motivo pelo qual a prevenção também se aplica na seara laboral.

Conforme visto, nos termos do artigo $7^{\circ}$. da $\mathrm{CR} / 88$ é dever do empregador e direito do empregado a redução dos riscos inerentes ao trabalho por meio de normas de saúde, higiene e segurança.

Nesse sentido, o legislador posiciona-se pela defesa da saúde do trabalhador e afirma a necessidade de melhoria das condições de trabalho do ponto de vista da saúde dos que trabalham (MANUS apud MELO, 2013).

Ainda o art. 196 da CR/88 reafirma a importância de políticas sociais e econômicas que visem à redução do risco de doenças e outros agravos.

O princípio da prevenção também é consagrado no citado art. 157, II, da CLT, que estabelece obrigações neste aspecto para as empresas:

Art. 157 - Cabe às empresas:

I - cumprir e fazer cumprir as normas de segurança e medicina do trabalho;

II - instruir os empregados, através de ordens de serviço, quanto às precauções a tomar no sentido de evitar acidentes do trabalho ou doenças ocupacionais;

III - adotar as medidas que lhes sejam determinadas pelo órgão regional competente;

IV - facilitar o exercício da fiscalização pela autoridade competente.

A prevenção dos infortúnios laborais não é uma obrigação apenas do empregador, mas, também, do empregado que deve cumprir as normas de saúde e segurança e auxiliar a empresa na identificação de situações de risco. Neste sentido, o artigo 158 da CLT:

Art. 158 - Cabe aos empregados:

I - observar as normas de segurança e medicina do trabalho, inclusive as instruções de que trata o item II do artigo anterior; 
Il - colaborar com a empresa na aplicação dos dispositivos deste Capítulo.

Parágrafo único - Constitui ato faltoso do empregado a recusa injustificada:

a) à observância das instruções expedidas pelo empregador na forma do item II do artigo anterior;

b) ao uso dos equipamentos de proteção individual fornecidos pela empresa.

A inobservância das normas de saúde e segurança por parte do empregado pode ensejar a sua dispensa por justa causa e, por parte do empregador multa aplicada pela fiscalização do trabalho, além das repercussões trabalhistas e previdenciárias, no caso de acidente por culpa patronal - indenização por dano material, moral e estético; fator acidentário de prevenção e ação regressiva acidentária.

A prevenção dos infortúnios laborais deve ser uma máxima dentro das empresas pois "nada 'paga' a vida de um ser humano e as consequências sociais e humanas decorrentes de um acidente laboral, sem se falar no grande custo para as empresas e para a economia do país" (MELO, 2013, p. 37).

A vida, a saúde e a integridade física e mental do obreiro precisam ser preservadas como tal, sendo a tutela ressarcitória padrão incompatível com a natureza desses bens. $\mathrm{O}$ ressarcimento pelo equivalente pecuniário é incapaz de recompor os prejuízos do trabalhador que perdeu a vida, a saúde ou a integridade física ou mental, que sofreu um dano moral ou um dano estético.

A prevenção pressupõe uma série de ações conjuntas e concertadas entre Poder Público, empregadores e empregados. É necessário que os empregadores se conscientizem de que os gastos com prevenção não constituem despesas e sim investimentos, pois diminuem despesas com indenizações, horas não trabalhadas, adicionais, acréscimo à contribuição previdenciária, multas, entre outras repercussões.

O investimento no funcionário por meio de uma postura patronal em prol da manutenção de um meio ambiente do trabalho seguro, saudável e livre de riscos é um fator de aumento da produtividade e, por 
conseguinte, do lucro. O empregado é essencial na dinâmica empresarial, devendo ser percebido e valorizado como tal.

Nesse contexto, percebemos que a prevenção passa por diversos aspectos, como a educação, a conscientização, o investimento e, também, pela questão processual, encontrando na tutela específica um importante meio de concretização.

\section{A TUTEla INIBITória: INSTRUMENTO DE PREVENÇÃo DE ACIDENTES DO TRABALHO E EFETIVAÇÃO DO DIREITO FUNDAMENTAL AO MEIO AMBIENTE DE TRABALHO EQUILIBRADO}

Por meio da análise histórico-legal percebemos que a conscientização e atuação da sociedade no que diz respeito aos riscos ambientais do trabalho vêm sendo gradual, assim como a conduta estatal.

Hoje, o direito à saúde do trabalhador e ao meio ambiente do trabalho equilibrado em nosso ordenamento jurídico é reconhecido pelas normas em número suficiente para garanti-lo. Normas com natureza jurídica de direito humano fundamental.

O desafio agora é que esse aparato legal seja efetivado de modo que o empregado tenha um ambiente de trabalho seguro e saudável, capaz de promover sua saúde e integridade física e mental. Em face da inobservância da norma pelo empregador, a postulação em juízo do bem da vida garantido passa a ser o meio de concretização do direito à saúde e segurança no trabalho (OLIVEIRA, 2011).

A tutela jurisdicional emerge como instrumento capaz de promover a saúde do trabalhador, devendo ser conferida de maneira rápida e eficaz para que se desestimulem as práticas nocivas e haja o resultado que interessa ao trabalhador, qual seja, um meio ambiente de trabalho equilibrado - seguro e saudável.

Nesse contexto, Sebastião Geraldo de Oliveira (2011) menciona a Recomendação Conjunta $n^{\circ}$. 1, de 3 de maio de 2011, expedida pelo Tribunal Superior do Trabalho com o Corregedor Geral da Justiça do Trabalho, que recomenda aos Desembargadores dos Tribunais Regio- 
nais do Trabalho e aos Juízes do Trabalho que deem prioridade à tramitação e ao julgamento das ações trabalhistas que envolvam acidente do trabalho.

A importância do assunto, tendo a proteção à vida, integridade e saúde como direitos humanos fundamentais dos obreiros, justifica o tratamento diferenciado.

Em razão disso, as tutelas de urgência vêm ganhando papel de destaque no processo do trabalho, bem como, as tutelas preventivas, para impedir a ocorrência do dano ou para que cessem seus efeitos.

A adoção de ações que promovam a prevenção de acidentes e a melhora do ambiente laboral encontra no instrumento processual da tutela específica e inibitória um grande aliado para a sua efetividade e uma alternativa à tutela ressarcitória padrão.

Apesar de toda modernidade e dos progressos observados ao longo dos anos na legislação pertinente, os números dos acidentes ainda são elevados ${ }^{9}$ e muitos trabalhadores se afastam do ambiente laboral em face de infortúnios que poderiam ser evitados. De acordo com José Carlos Barbosa Moreira:

Não há dúvida de que a tutela específica é superior e deve ser preferida, sempre que possível, a qualquer outra forma. O que o ordenamento jurídico quer é que os deveres e obrigações se cumpram tais quais são. Se a alguém é dado pretender, segundo o direito, que outrem se abstenha de algo, há de poder contar com o direito para conseguir a utilidade que espera da abstenção - essa utilidade, e não outra, "equivalente" que seja, ou inculcada como tal. $\mathrm{E}$ a necessidade de recorrer às vias judiciais para obter proteção nada altera, em princípio, no quadro: se o processo constitui instrumento para a realização do direito material, só se pode a rigor considerar plenamente eficaz a sua atuação quando ele

9 Tal assertiva se comprova por meio dos dados constantes nos Anuários Estatísticos da Previdência Social disponível em: $<$ http://www.previdencia.gov.br/dados-abertos/>. Acesso em: 2 jul. 2016. 
se mostre capaz de produzir resultado igual ao que se produziria se o direito material fosse espontaneamente observado (MOREIRA, 1988, p. 31-32).

$\mathrm{O}$ ordenamento jurídico brasileiro estabelece o dever de promoção da saúde do trabalhador como sendo do Estado e dos particulares, conforme o exposto na CR/88, CLT e outras leis ordinárias, além de convenções internacionais ratificadas.

Essas normas compõem um amplo sistema tendente à prevenção do risco e à promoção de condições dignas de trabalho, oferecendo base suficiente para a implantação do modelo prevencionista dos riscos ambientais.

No entanto, o que se observa é um quadro onde prevalecem a tutela ressarcitória e o descumprimento reiterado dos direitos relativos à saúde e segurança do obreiro.

A prevenção dos acidentes do trabalho é um direito fundamental, e sua eficácia social, ou seja, sua efetividade deve orientar a aplicação das normas sobre a saúde do trabalhador e o meio ambiente do trabalho.

Nesse sentido, a tutela específica e inibitória ${ }^{10}$ tem caráter preventivo do dano e tende a compelir o devedor ao adimplemento da obrigação in natura, servindo assim à concretização do direito social à prevenção, fazendo que, por meio do processo, esse direito seja satisfeito de modo tempestivo, adequado e eficaz, eliminando o distanciamento entre o que é prometido pelo direito material, e o que é obtido através do processo.

A tutela específica das obrigações de fazer deve ser usada na adoção de medidas voltadas para a extinção ou redução máxima dos riscos inerentes ao meio ambiente do trabalho.

10 O tema da tutela específica e o direito material e processual do trabalho tem ganhado relevo, sendo objeto de diversos estudos. Nesse sentido, a dissertação de Mestrado intitulada "Tutela inibitória como instrumento de prevenção contra o assédio moral: a efetividade da jurisdição trabalhista na proteção de direitos de natureza extrapatrimonial" defendida pelo Juiz do Trabalho Eduardo Rockenbach Pires, em 2011, na Faculdade de Direito da USP. Disponível em: http://www.teses.usp.br/teses/disponiveis/2/2138/tde-28012015-075037/pt-br.php Acesso em: 19 out. 2016. 
Nesse contexto, a tutela inibitória atua como instrumento processual com objetivo preventivo, especificamente para impedir que o ilícito venha a se materializar em um dano, consistindo na determinação do cumprimento de uma obrigação de fazer ou não fazer, ou ainda, em medidas diversas que sejam necessárias para afastar ou impedir a ocorrência do dano (OLIVEIRA, 2011).

Paulo Ricardo Pozzolo define a tutela inibitória como:

[...] aquela que visa a prevenção da prática, da repetição ou da continuação de uma conduta ilícita ou danosa, positiva ou negativa, contratual ou extracontratual. Tutela porque visa sempre a proteção de um bem da vida. A tutela inibitória dirige-se contra o ilícito, ainda que não cause dano material, mas volta-se também contra o dano, mesmo que a conduta não seja necessariamente ilícita. Tal entendimento decorre da possibilidade de ocorrerem condutas ilícitas que não causem dano; ou condutas lícitas danosas. Em ambas o interesse do eventual prejudicado deve ser protegido. Referida tutela protege tanto contra a conduta ilícita ou danosa derivada de um fazer (positiva), quanto a de um não fazer (negativa), voltando-se para obrigações contratuais e extracontratuais (POZZOLO, 2010).

O primeiro fundamento da tutela inibitória é assinalado no artigo $5^{\circ}$. da $\mathrm{CR} / 88$ que, em seu inciso XXXV, estabelece que "a lei não excluirá da apreciação do Poder Judiciário lesão ou ameaça a direito". Ou seja, todos têm acesso à justiça para postular tutela jurisdicional preventiva ou reparatória de um direito individual, coletivo ou difuso.

Ter direito constitucional de ação significa poder deduzir pretensão em juízo e também poder dela defender-se. O princípio constitucional do direito de ação garante ao jurisdicionado o direito de obter do Poder Judiciário a tutela jurisdicional adequada, caracterizada como tutela provida da efetividade e eficácia que dela se espera (NERY JR; NERY, 2013).

A norma assegura as tutelas preventivas para proteger direito ameaçado. Basta, portanto, a probabilidade do ilícito, ou seja, a ameaça ao 
direito do trabalhador de ter um ambiente de trabalho seguro e equilibrado, para ser cabível o uso da referida medida.

A tutela específica encontra guarida no art. 536 e art. 537 do NCPC aplicado subsidiariamente ao Direito Processual do Trabalho diante da lacuna normativa e compatibilidade, nos termos do art. 769 da CLT. ${ }^{11}$

De acordo com o art. 536 do CPC/15 "no cumprimento de sentença que reconheça a exigibilidade de obrigação de fazer ou de não fazer, o juiz poderá, de ofício ou a requerimento, para a efetivação da tutela específica ou a obtenção de tutela pelo resultado prático equivalente, determinar as medidas necessárias à satisfação do exeqüente".

A tutela inibitória é espécie da tutela específica, que visa garantir ao jurisdicionado exatamente o que a lei lhe garante e não o equivalente pecuniário.

A tutela específica subdivide-se em tutela reintegratória, tutela ressarcitória in natura e tutela inibitória. Essa tutela é contra o ilícito (e não contra o dano). O sujeito vai a juízo e afirma haver a iminência de ocorrência de um ilícito, e não um dano.

Ela garante o direito de não ter contra si a prática de um ilícito, independente deste causar dano, não havendo discussão de culpa ou dano no processo por serem temas estranhos à tutela inibitória.

$\mathrm{Na}$ tutela inibitória, então, se discute se há o risco de ocorrência do ilícito e se a conduta realmente é contrária ao Direito. O direito do trabalhador a um ambiente seguro e equilibrado não é adequadamente tratado apenas com a tutela ressarcitória, uma vez que o bem que se protege, quando ofendido, não pode ser restabelecido por meio do equivalente pecuniário. A vida, a integridade e a saúde não são recompostas com pecúnia, ao contrário, devem ser protegidas como tal por meio da prevenção de ocorrência do dano.

Por esse motivo, faz-se necessária a aplicação da tutela inibitória, dada a sua natureza preventiva, que visa impedir a prática de um ilícito, sua repetição ou continuação.

11 No mesmo sentido, a IN 39 do TST (editada pela Resolução n. 203, de 15 de março de 2016), art. $3^{\circ}$., XII, que também defende a aplicação subsidiária. Disponível em: $\quad<$ http://www.tst.jus.br/documents/10157/429ac88e-9b78-41e5-ae28-2a5f8a27f1fe $>$. Acesso em: 10 jul. 2016. 
Diante do descumprimento legal por parte do empregador, o ajuizamento de ação trabalhista com pedido de tutela inibitória emerge como um importante instrumento processual para a prevenção de acidentes do trabalho e doenças ocupacionais, visto que se trata de tutela que se destina a evitar a ocorrência de atos contrários às normas jurídicas e a impedir o vilipêndio a direitos que não podem ser adequadamente reparados pelo seu equivalente pecuniário.

Diante da insuficiência da tutela ressarcitória pelo equivalente pecuniário, a tutela específica obriga o réu a cumprir determinada obrigação, mediante o uso, se necessário, de medidas coercitivas.

O juiz fixa ao réu prazo para adimplemento da obrigação e comina, para o caso de descumprimento da decisão, a aplicação de multa diária ou outra medida coercitiva a ser instituída conforme a necessidade e a conveniência do caso.

Além das medidas coercitivas, o juiz pode se valer das medidas sub-rogatórias, a exemplo da busca e apreensão, da remoção de pessoas ou coisas, da interdição de estabelecimento, da paralisação de atividade nociva e outras.

Cumpre salientar que ações individuais com esse objetivo raramente são vistas na justiça do trabalho, pelo receio do desemprego ou retaliações, por ignorância quanto aos direitos e também pelo fato de que na doutrina jurídico-trabalhista predomina a cultura dos adicionais compensatórios e indenizações. Além disso, a condenação nas obrigações de fazer não implica valores patrimoniais, por isso não há estímulos para advogados e sindicatos no patrocínio dessas reclamações (MELO, 2011).

Assim, ganha força o papel do Ministério Público do Trabalho e dos Sindicatos na defesa dos direitos metaindividuais dos trabalhadores mediante o uso da tutela específica, com preferência à tutela inibitória. A ação civil pública tem representado meio processual adequado e eficaz à tutela dos citados direitos.

Tanto na perspectiva individual quanto coletiva, deve o jurisdicionado se valer dos instrumentos processuais postos com o objetivo de dar concretude ao direto fundamental ao ambiente de trabalho equili- 
brado que compreende a proteção da saúde do trabalhador e prevenção dos acidentes do trabalho.

\section{CONSIDERAÇÕES FINAIS}

A dignidade da pessoa humana e o valor social do trabalho, fundamentos da República Federativa do Brasil e princípios constitucionais, não se dão de forma plena se o direito do trabalhador a um ambiente de trabalho equilibrado não for respeitado.

Um ambiente de trabalho equilibrado é aquele seguro e salutar, em que não há ameaça à saúde e integridade física e mental do trabalhador, tampouco ocorrência de acidentes do trabalho e seus reflexos negativos - pessoais, empresariais, sociais.

É importante salientar que a prevenção de acidentes e doenças do trabalho deve nortear as estratégias das empresas no sentido de priorizar ações e investimentos que proporcionem o alcance desse objetivo.

Além de prevenir acidentes e doenças, um ambiente de trabalho equilibrado previne também gastos com custas judiciais, indenizações, tratamentos de saúde, benefícios e serviços previdenciários com a vítima do infortúnio.

Nosso ordenamento jurídico dispõe de um amplo conjunto normativo para proteger a saúde e integridade física e mental do trabalhador. Essas normas carecem de efetividade para que surtam reais efeitos no mundo dos fatos.

Nesse contexto, emerge a tutela inibitória como um instrumento eficaz no sentido de dar concretude à lei material, especificamente no que diz respeito à proteção do meio ambiente de trabalho por meio da obrigação de torná-lo, como já foi dito, seguro e salutar, livre de ameaças à saúde e integridade física e mental do trabalhador.

A tutela inibitória é instrumento de efetividade ao que é garantido pelo ordenamento jurídico. Por meio dela, a prevenção prevalece sobre a tutela ressarcitória pelo equivalente pecuniário. O uso faz-se necessário nas esferas individuais e metaindividuais, com especial atuação do Ministério Público do Trabalho e sindicatos. 
Com isso, os ganhos para os trabalhadores e também para os empregadores se traduzem numa relação de emprego onde prevalece o princípio da dignidade da pessoa humana, o valor social do trabalho, o direito fundamental a um meio ambiente de trabalho equilibrado, à saúde do obreiro e à prevenção de infortúnios.

\section{REFERÊNCIAS}

A Revolução Industrial e as fábricas - Segurança no trabalho. Disponível em $<$ http/www.portaleducacao.com.br/educacao/artigos/45782/arevolucao-industrial-e-as-fabricas-seguranca-no-trabalho\#>. Acesso em: 5 abr. 2015.

CARMELLO, Eduardo. Qualidade De Vida No Trabalho. 15/08/2013. Disponível em: <http://www.rhportal.com.br/artigos/rh.php?idc_cad=a7o2sdrwi $>$. Acesso em: 3 abr. 2015.

CARRION, V. Comentários à Consolidação das leis do trabalho, 35. ed. atual. por Eduardo Carrion. São Paulo: Saraiva, 2010.

CASSAR, Vólia Bomfim. Direito do Trabalho, 9. ed. Método, 02/2014. VitalBook file.

COSTA, M., organizador; CHINELlATO, S. J., coordenadora. Código Civil Interpretado: artigo por artigo, parágrafo por parágrafo, 6. ed. Barueri, SP: Manole, 2013.

ENDO, M. L. Meio ambiente do trabalho - segurança e saúde do trabalhador: Espaço não adequado ao trabalhador representa agressão à sociedade. Disponível em: <http://www.rumosustentavel.com.br/meio-ambiente-do-trabalho-seguranca-e-saude-do-trabalhador-espaco-nao-adequado-ao-trabalhador-representa-agressao-a-sociedade/>. Acesso em: 7 mar. 2015.

GEMIGNANI, T. A. A.; GEMIGNANI, D. Meio ambiente de trabalho. Precaução e Prevenção. Princípios norteadores de um novo padrão normativo. Rev. TST, Brasília, v. 78, n. 1, jan./mar. 2012.

Lei de Política Nacional do Meio Ambiente. Disponível em: www.planalto. gov.br/ ccivil_03/leis/16938.htm. Acesso em 2 abr. 2015. 
LEDUR, José Felipe. A realização do direito ao trabalho. Porto Alegre: Sergio Antonio Fabris, 1998.

MELO, R. S. Direito Ambiental do trabalho e a saúde do trabalhador, 5. ed. São Paulo: LTr, 2013.

MENDES, René; DIAS, Elizabeth Costa. Da medicina do trabalho à saúde do trabalhador. Rev. Saúde Pública, v. 25 n. 5. São Paulo out. 1991.

MORAES, Alexandre de. Direitos humanos fundamentais, 2. ed. São Paulo: Atlas, 1998.

MOREIRA, J. C. B. Temas de Direito Processual: segunda série, 2. ed. São Paulo: Saraiva, 1988.

NERY JR, N.; NERY, R. M. A. Constituição Federal Comentada e legislação constitucional, 4. ed. rev. atual e ampl. São Paulo: Editora Revista dos Tribunais, 2013.

OLIVEIRA, S. G. Proteção jurídica à saúde do trabalhador, 6. ed. rev. e atual. São Paulo: LTr, 2011.

POZZOLO, P. R. Aplicação da tutela inibitória no processo do trabalho.

Disponível em: <http://www.trt9.jus.br/apej/artigos_doutrina_prp_01.asp>. Acesso em: 4 jul. 2015.

ROCHA, J. C. de S. da. Direito Ambiental e meio ambiente do trabalho: dano, prevenção e proteção jurídica. São Paulo: LTr, 1997.

SILVA, José Afonso da. Curso de direito constitucional positivo, 16. ed. rev. e atual. nos termos da reforma cons. São Paulo: Malheiros, 1999.

Dados dos Autores

\section{Vitor Salino de Moura Eça}

Doutor em Direito Processual pela Pontifícia Universidade Católica de Minas Gerais. Juiz do trabalho titular - Tribunal Regional do Trabalho - 3a. Região - MG, Professor Adjunto IV da Pontifícia Universidade Católica de Minas Gerais. Belo Horizonte/MG - Brasil. vitorsalino@gmail.com 


\section{Aline Carneiro Magalhães Carvalhido}

Doutoranda em Direito pela Pontifícia Universidade Católica de Minas Gerais. Professora do Ensino Superior. Palestrante. Articulista. Advogada. Belo Horizonte/MG - Brasil. alinecmagalhaes@gmail.com

\section{Flávia Aparecida Oliveira Pierre}

Graduada em Administração pela Faculdade Governador Ozanam Coelho. Professora e Coordenadora do curso de Gestão Empresarial. Juiz de Fora/MG

- Brasil. flavia.oliveiravv@gmail.com

Submetido em: 15-08-2016

Aceito em: 17-10-2016 